\title{
A portable calorimeter for measuring liquid-water content of wet snow
}

\author{
Katsuhisa Kawashima, ${ }^{1}$ Toru Endo, ${ }^{1}$ Yukari Takeuchi ${ }^{2}$ \\ ${ }^{1}$ Shiozawa Snow Testing Station, Railway Technical Research Institute, Shiozawa, Niigata 949-64, Japan \\ ${ }^{2}$ Nagaoka Institute of Snow and Ice Studies, NIED, Nagaoka, Niigata 940, Japan
}

\begin{abstract}
In order to facilitate the measurement of liquid-water content of snow in high mountains, a portable calorimeter named "Endo-type snow-water content meter" was developed. It is composed of a metal-coated container made of insulating materials and a lid of the container with a small-thermistor thermometer. Its strong points are its light weight, small size and easy fabrication with cheap materials. The total weight of the device is as light as $250 \mathrm{~g}$, which is less than $10 \%$ of the snow-water content meter widely used in Japan (Akitaya-type snow-water content meter). The results of experiments have revealed that the device is capable of measuring the liquid-water content within 2 minutes with an accuracy of $2 \%$ by weight.
\end{abstract}

\section{INTRODUGTION}

It is well known that snow rapidly changes its structure when containing liquid water. Since the mechanical property of wet snow depends greatly on the amount of liquid water in snow, the measurement of liquid-water content is important in clarifying the dynamic behaviour of wet snow.

There are various methods which have been used to measure the liquid-water content of snow: a centrifugal method (Kuroda and Furukawa, 1952; LaChapelle, 1956), a melting calorimetry (Yosida, 1960), a freezing calorimetry (Radok and others, 1961; Jones and others, 1983) and a dielectric method (Kuroiwa, 1951; Ambach and Denoth, 1972). Recently, new methods for making field measurements of liquid-water content, including a solution method (Morris, 1981), a time-domain reflectometry (Stein and Kane, 1983), a dilution method (Davis and others, 1985) and an alcohol calorimetry method (Fisk, 1986) have been proposed. Comparative measurements of each method and each device have been made to assess the measurement accuracy and operating performance (Denoth and others, 1984; Boyne and Fisk, 1990).

Recently, in Japan, the melting calorimeter, designed by Akitaya $(1978,1985)$, has been widely used for measuring liquid-water content. This method uses hot water and has the advantage of faster measurement than the freezing calorimeter, because the thermal equilibrium between hot water and the snow sample can be reached quickly. However, the Akitaya-type snow-water content meter has several disadvantages due to its large size, heavy weight and time-consuming operation, which causes a transportation problem and a poor efficiency of measurement in making observations in high mountains. In addition, Colbeck (1978) has concluded from error analysis that melting calorimetry is inherently inaccurate. Does this imply that melting calorimetry is of no practical use? It may be necessary to reexamine the measurement error for melting calorimetry.

To solve the above problems of the Akitaya-type snow- water content meter, we have designed a portable melting calorimeter (Endo-type snow-water content meter) suitable for use in the mountains. In this paper, the structure, procedure and accuracy of the new device is described to show its practical advantages.

\section{STRUCTURE OF THE DEVICE}

The schematic diagram and side view of the Endo-type snow-water content meter are shown in Figures 1 and 2, respectively. It is composed of a container and a lid made of insulating materials (styrene foam). For durability, the container is put in a metal canister with a wall thickness of $1.5 \mathrm{~mm}$. A small thermistor with a digital display, whose weight and resolution are $60 \mathrm{~g}$ and $0.1^{\circ} \mathrm{C}$, respectively, is attached to the lid of the container to measure the temperature of water poured into it. The joint between the container and its lid contains a tapered structure, which allows easy installation and removal of the lid, together with airtight-

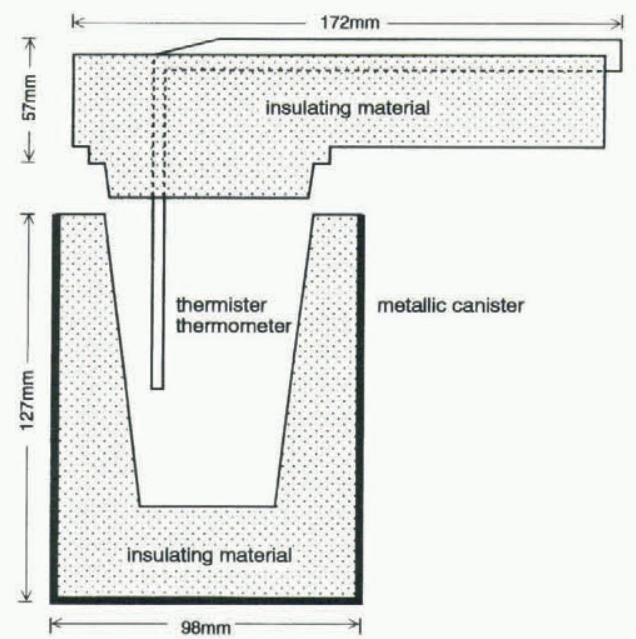

Fig. 1. Schematic diagram of Endo-type snow-water content meter. 


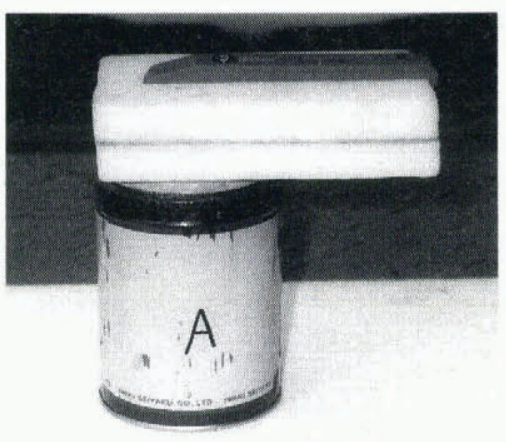

Fig. 2. Side-view of Endo-type snow-water content meter.

ness of the container. The weight and volume of the Endotype snow-water content meter are $250 \mathrm{~g}$ and $1.6 \times 10^{3} \mathrm{~cm}^{3}$, respectively, showing that they are no more than $10 \%$ of those of the Akitaya-type snow-water content meter.

\section{MEASURING PROGEDURES}

Measuring procedures of liquid-water content by the Endotype snow-water content meter are as follows: (1) 60-100 $\mathrm{cm}^{3}$ of hot water $\left(30-40^{\circ} \mathrm{C}\right)$ are put into a small vessel and its mass, $M_{1}$, is measured. (2) The vessel is emptied of hot water by pouring into the container of the device and then the mass of the empty vessel, $M_{2}$, is measured. (3) After the lid is put on the container, the total mass of the device, including the hot water, $M_{3}$, is measured. (4) The temperature of the hot water, $T_{1}$, is read on the thermometer while shaking the device. (5) Soon after the snow is taken with a cylindrical sampler which has been stored in the snow adjacent to the sampling site, the lid is taken off for an instant and then the sample $(20-30 \mathrm{~g})$ is put into the container. The snow sample is quickly melted by shaking the device, resulting in a rapid drop in temperature of the hot water. When the thermometer provides a stable temperature, $T_{2}$, we read it. (6) The total mass of the device, including hot water and snow sample, $M_{4}$, is measured.

The liquid-water content, $W$, is defined as the ratio of the water weight to the total weight of wet snow in per cent, and can be calculated by

$$
W=100\left[1-\frac{C}{L}\left\{\frac{\left(M_{1}-M_{2}\right)\left(T_{1}-T_{2}\right)}{M_{4}-M_{3}}-T_{2}\right\}\right]
$$

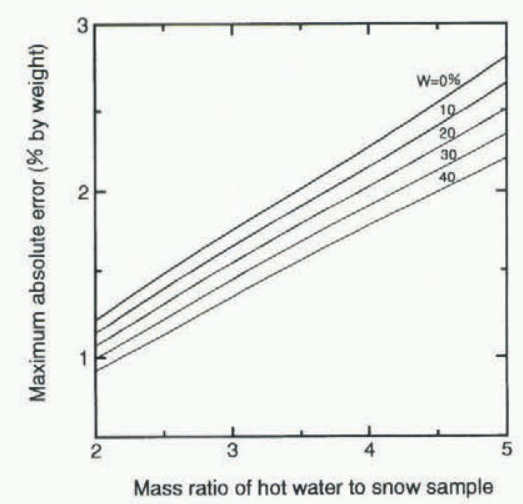

Fig. 3. Maximum absolute error $(|\delta W|)$ in the measurement of liquid-water content by the Endo-type snow-water content meter as a function of mass ratio of hot water to snow sample (R). where $C$ is the specific heat of water $\left(4.2 \times 10^{3} \mathrm{~J} \mathrm{~kg}^{-1} \mathrm{~K}^{-1}\right), L$ is the latent heat of fusion of ice $\left(3.34 \times 10^{5} \mathrm{~J} \mathrm{~kg}^{-1}\right) . M_{1}, M_{2}$, $M_{3}$ and $M_{4}$ are determined with an accuracy of $10^{-4} \mathrm{~kg}$, and $T_{1}$ and $T_{2}$ in Celsius with an accuracy of $0.1^{\circ} \mathrm{C}$.

\section{ERROR ANALYSIS}

The liquid-water content is a function of six directly measured values and can be described as

$$
W=f\left(T_{1}, T_{2}, M_{1}, M_{2}, M_{3}, M_{4}\right) .
$$

The maximum value of expected absolute error in the indirect measurement of liquid-water content, $|\delta W|$, is derived by

$$
|\delta W|=\sum_{i=1}^{2}\left|\frac{\partial f}{\partial T_{i}} \delta T_{i}\right|+\sum_{j=1}^{4}\left|\frac{\partial f}{\partial M_{j}} \partial M_{j}\right|
$$

where $\delta T_{i}$ and $\delta M_{j}$ are the errors in the direct measurements of $T_{i}$ and $M_{j}$, respectively.

Equation (3) becomes

$$
\begin{aligned}
|\partial W| & =100\left[k R \delta T_{1}+k(R-1) \delta T_{2}\right. \\
& \left.+\frac{1+k T_{2}-W}{M_{1}-M_{2}}\left\{\delta M_{1}+\delta M_{2}+R\left(\delta M_{3}+\delta M_{4}\right)\right\}\right]
\end{aligned}
$$

where

$$
k=\frac{C}{L}
$$

and

$$
R=\frac{M_{1}-M_{2}}{M_{4}-M_{3}} .
$$

For a typical case where $\delta T_{1}=\delta T_{2}=0.1^{\circ} \mathrm{C}, \delta M_{1}=$ $\delta M_{2}=\delta M_{3}=\delta M_{4}=10^{-4} \mathrm{~kg}, T_{2}=10^{\circ} \mathrm{C}$ and $M_{1}-M_{2}=$ $8 \times 10^{-2} \mathrm{~kg}$.

$$
|\delta W|=0.16+0.53 R-0.25(R+1) W .
$$

Figure 3 shows the maximum absolute error as a function of $R$ for various values of $W$. This clearly indicates that $|\delta W|$ increases when $R$ is large or $W$ is small. If we need an error of $|\delta W| \leq 2 \%$ irrespective of $W$, it is required to keep $R<3.5$. Thus, it can be concluded from the error analysis that the melting calorimeter proposed in this study is practically available, if special attention is given to the mass ratio of the hot-water-to-snow sample.

\section{EXPERIMENTAL MEASUREMENTS}

\section{Measurement accuracy}

To estimate how accurately the liquid-water content can be determined with the Endo-type snow-water content meter, 49 samples of wet snow having known values of liquid-water content, $W_{0}$, were artificially made in a cold room by adding known quantities of water at a temperature of $0^{\circ} \mathrm{C}$ to known quantities of dry snow at a temperature of $0^{\circ} \mathrm{C}$. Measurements of liquid-water content by this device were made in a cold room controlled to $0^{\circ} \mathrm{C}$ and then measured values, $W$, were compared with $W_{0}$.

In Figure $4, W$ is plotted against $W_{0}$, showing a linear relationship expressed approximately as

$$
W=1.006 W_{0}+0.164 \text {. }
$$

Statistical considerations indicate that the average error and the probable error are 1.07 and $0.903 \%$, respectively. About $86 \%$ of $W$ fall in the range within $W_{0} \pm 2 \%$. These 


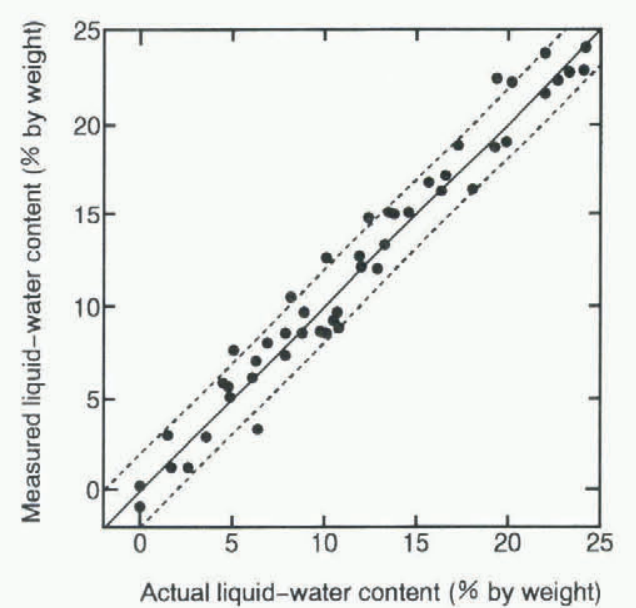

Fig. 4. Relation between values of liquid-water content ( $\left.W_{0}\right)$ and those measured by the Endo-type snow-water content meter $(W)$. Solid and broken lines represent $W=W_{0}$ and $W=W_{0} \pm 2 \%$, respectively.

imply that the device is capable of measuring liquid-water content with an accuracy of $2 \%$ by weight in most cases, which is consistent with the result of error analysis. Furthermore, in spite of the fact that no consideration is given to the effect of heat flow from hot water to the container in Equation (1), the data shown in Figure 4 are evenly distributed above and below the line which represents $W=W_{0}$, suggesting that this effect is negligible.

\section{Effect of heat loss by opening the lid}

When the lid is kept open to put a snow sample into the container, heat loss can occur through the open top of the container. To estimate the effect of the time the lid is kept open on the measured liquid-water content, snow samples having a water content of $10 \%$ were prepared in the same manner as mentioned above and were measured by the Endo-type snow-water content meter with the opened time being changed from $2 \mathrm{~s}$ to $100 \mathrm{~s}$. Two series of measurements were made when the temperature of hot water was $34^{\circ}$ and $40^{\circ} \mathrm{C}$. Changes in liquid-water content due to the opened time are shown in Figure 5. Roughly constant values of 9-12\% up to a time of $40 \mathrm{~s}$ are followed by a sudden decrease in liquidwater content in the case of a temperature of $34^{\circ} \mathrm{C}$, while a sudden decrease begins at a time of only $10 \mathrm{~s}$, when the hot water has a temperature of $40^{\circ} \mathrm{C}$. Consequently, we can conclude that the opened time does not have a significant effect on the measured value, if the temperature of hot water does not exceed $40^{\circ} \mathrm{C}$, because the opened time is usually as little as about $2 \mathrm{~s}$.

\section{Comparison with other devices}

Three profiles of liquid-water content were obtained at Nagaoka, Japan on 7 March 1996 using the Endo-type snow-water content meter, the Akitaya-type snow-water content meter and the snow-surface/volume-wetness dielectric device. The last device was developed at the Institute for Experimental Physics, University of Innsbruck, to determine a volumetric liquid-water content which can be transformed into a gravimetric one by use of the snow density. Measuring points are horizontally spaced at $5 \mathrm{~cm}$ intervals for each profile. The results are shown in Figure 6, together with the density profile and stratigraphy of the snow cover.

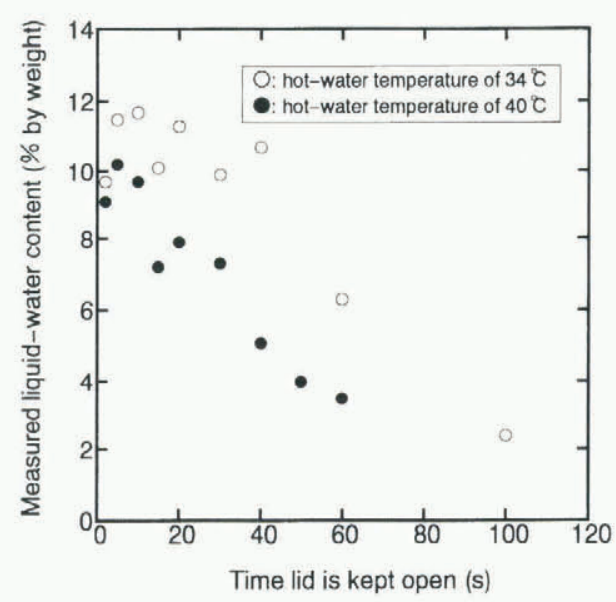

Fig. 5. Changes in liquid-water content measured by the Endo-type snow-water content meter due to the time the lid of the device is kept open. Snow samples with a liquid-water content of $10 \%$ were measured. Open circles and solid circles represent the measured values when the temperature of the hot water is $34^{\circ}$ and $40^{\circ} \mathrm{C}$, respectively.

The snow cover was entirely metamorphosed into a coarsegrained granular snow with densities of $330-490 \mathrm{~kg} \mathrm{~m}^{-3}$. Comparisons between three profiles of liquid-water content show an approximate agreement between the three, although the difference in measured values reaches $5 \%$ or more at heights of 14,36 and $70 \mathrm{~cm}$. These significant differences, however, are not necessarily attributable to the difference of the measuring device, because the structure and properties of the snow cover become heterogeneous during the melt season.

Using the Endo-type snow-water content meter and the snow-surface/volume-wetness dielectric device, the liquidwater content was measured at the same depth of the snow cover to compare measured values by them. Measured points for each device were horizontally spaced about $5 \mathrm{~cm}$ apart. A coarse-grained granular snow with densities of $310-520 \mathrm{~kg} \mathrm{~m}^{-3}$ was used for the measurements. The results,

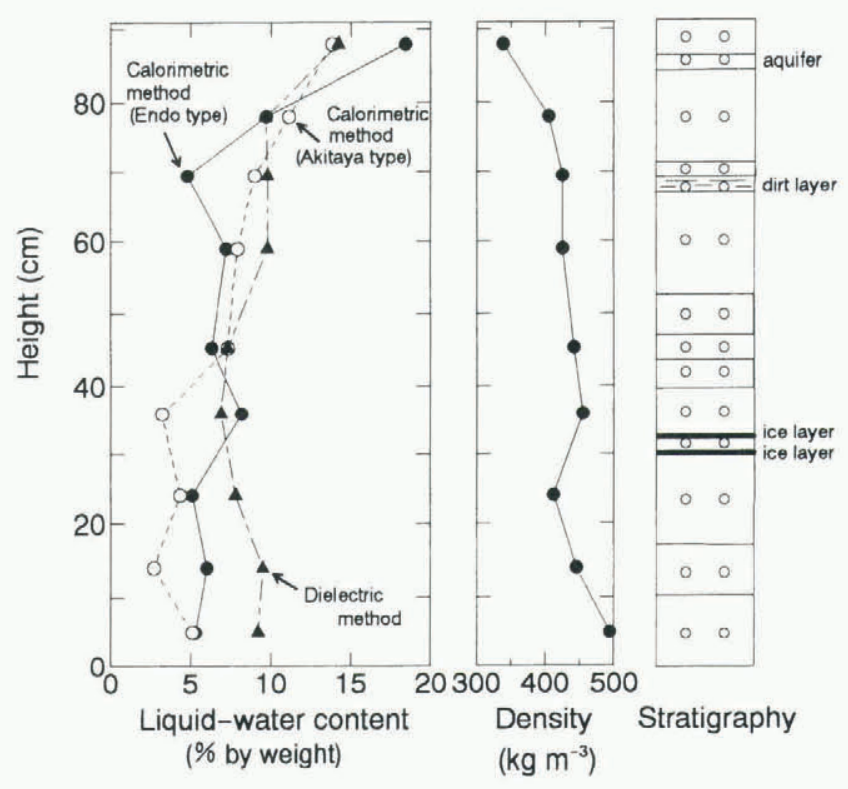

Fig. 6. Liquid-water content, density profiles and stratigraphy of the snow cover at Nagaoka on 7 March 1996. Grain-shape classification is referred to Colbeck and others (1990). 
shown in Figure 7, indicate a switching relation between the measured value by the calorimetric method and that by the dielectric method; the former is smaller than the latter at lower water contents and the reverse is true at higher water contents. In other words, the latter has a tendency to fall in a narrower range in comparison with the former. Although the reason for this is not clear, it may be possible that the water-saturation regime and the grain structure in wet snow exert an effect on the determination of liquid-water content by the dielectric method.

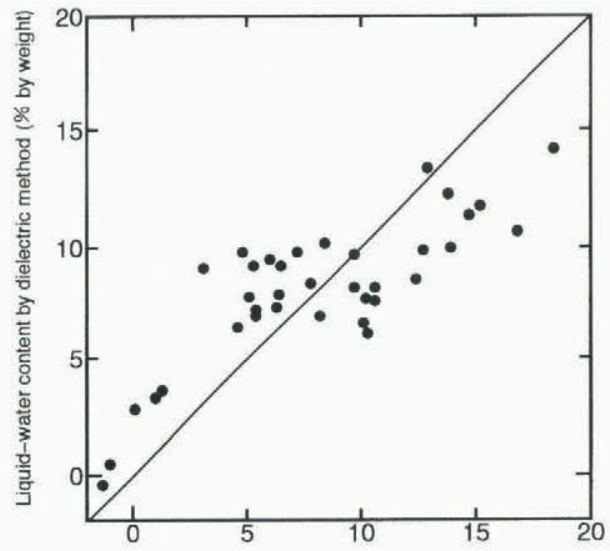

Liquid-water content by Endo-type calorimeter ( $\%$ by weight)

\section{Fig. 7. Liquid-water content measured by a dielectric method in comparison with those by Endo-type snow-water content meter.}

During the observation shown in Figure 6, we could obtain the time required for each measurement of liquidwater content, which was made by two persons including an operator and a recorder. The mean time necessary for a measurement was calculated for the three types of device (Table l). As a result, 2 minutes were found to suffice for a measurement by the Endo-type snow-water content meter and the dielectric device, whereas about 4 minutes were needed for a measurement by the Akitaya-type snow-water content meter. The Endo-type snow-water content meter is superior in measurement rate to the freezing calorimeter (Jones and others, 1983), the dilution method (Davis and others, 1985) and the alcohol calorimeter (Fisk, 1986) by a factor of at least 2.

\section{GONGLUSIONS}

A portable melting calorimeter was developed for measuring liquid-water content of snow by weight. Its major advantages lie in its light weight and small size, together with easy fabrication with cheap materials. The time required for a measurement by the device is as little as 2 minutes, which provides a benefit of much speedier measurements than the current device in Japan. Furthermore, the measurement accuracy is within $\pm 2 \%$ by weight and is not practically inferior to other snow-water content meters. For these reasons, the new device is suitable for measurements in high mountains where measuring instruments must be transported using human power. On the other hand, it is important to recognize that measured values using this device are sensitive to the natural heterogeneity of water distribution in the snow cover, because rather small snow samples are used for the measurements.
Table 1. Mean time required for the measurement of liquidwater content for three types of snow-water content meter

Device

Necessary time

s

$\begin{array}{lc}\text { Endo type } & 105 \\ \text { Akitaya type } & 236 \\ \text { Dielectric method } & 94\end{array}$

\section{ACKNOWLEDGEMENTS}

The authors wish to express their appreciation to T. Kobayashi and Y. Nohguchi, National Research Institute for Earth Science and Disaster Prevention, and K. Izumi, Niigata University, for their encouragement and for many useful suggestions. The authors are greatly indebted to M. Shimizu, Y. Yamada and T. Ikarashi, National Research Institute for Earth Science and Disaster Prevention, for providing measuring instruments. The authors are also thankful to K. Nishimura and Y. Ito, Hokkaido University, for their kind cooperation in the field observations.

\section{REFERENCES}

Akitaya, E. 1978. [Measurements of free water content of wet snow by calorimetric method.] Low Temp. Sci., Ser. A 36, 103-111. [In Japanese with English summary.]

Akitaya, E. 1985. A calorimeter for measuring free water content of wet snow. Ann. Glaciol., 6, 246-247.

Ambach, W. and A. Denoth. 1972. Studies on the dielectric properties of snow. Z Gletscherkd. Glazialgeol., 8(1-2), 113-123.

Boyne, H. S. and D. J. Fisk. 1990. A laboratory comparison of field techniques for measurement of the liquid water fraction of snow. CRREL Spec. Rep. 90-3.

Colbeck, S. C. 1978. The difficulties of measuring the water saturation and porosity of snow. 7. Glaciol., 20 (82), 189-201.

Colbeck, S. C. and 7 others. 1990. The international classification for seasonal snow on the ground. Wallingford, Oxon, International Association of Scientific Hydrology. International Commission on Snow and Ice.

Davis, R. E., J. Dozier, E. R. LaChapelle and R. Perla. 1985. Field and laboratory measurements of snow liquid water by dilution. Water Resour. Res., $21(9), 1415-1420$.

Denoth, A. and 6 others. 1984. A comparative study of instruments for measuring the liquid water content of snow. 7. Appl. Phys., 56 (7), 2154-2160.

Fisk, D. 1986. Method of measuring liquid water mass fraction of snow by alcohol solution. 7. Glaciol., 32(112), 538-539.

Jones, E. B., A. Rango and S. M. Howell. 1983. Snowpack liquid water determinations using freezing calorimetry. Nord. Hydrol., 14(3), 113-126.

Kuroda, M. and I. Furukawa. 1952. [Measurement of water content of snow deposit.] Seppyo, 7. Jpn. Soc. Snow Ice, 13(4), 144-152. [In Japanese with English summary.]

Kuroiwa, D. 1951. [The dielectric behaviour of snow cover.] Low Temp. Sci., Ser. A 8, 1-57. [InJapanese with English summary.]

LaChapelle, E. R. 1956. The centrifugal separation of free water from melting snow. J. Glaciol., 2(20), 769-771/763.

Morris, E. M. 1981. Field measurement of the liquid-water content of snow. 7. Glaciol., 27(95), 175-178.

Radok, U., S. K. Stephens and K. L. Sutherland. 1961. On the calorimetric dtermination of snow quality. International Association of Scientific Hydrology Publication 54 (General Assembly of Helsinki 1960 - Snow and Ice), 132 135.

Stein, J. and D. L. Kane. 1983. Monitoring the unfrozen water content of soil and snow using time domain reflectometry. Water Resour. Res., 19 (6), 15731584.

Yosida, Z. 1960. A calorimeter for measuring the free water content of wet snow. J. Glaciol., 3(27), 574-576. 